Research Article

\title{
Multiobjective Optimization Design of Toll Plaza
}

\author{
Kai Wang $\mathbb{D}^{1},{ }^{1}$ Peng Wang, ${ }^{2}$ Xin Chen, ${ }^{2}$ and Lu-Ting Zhao ${ }^{2}$ \\ ${ }^{1}$ School of Science, Anhui Agricultural University, Hefei 230036, China \\ ${ }^{2}$ School of Engineering, Anhui Agricultural University, Hefei 230036, China \\ Correspondence should be addressed to Kai Wang; kaywang@163.com
}

Received 7 August 2020; Accepted 30 September 2020; Published 27 October 2020

Academic Editor: Jia-Bao Liu

Copyright (c) 2020 Kai Wang et al. This is an open access article distributed under the Creative Commons Attribution License, which permits unrestricted use, distribution, and reproduction in any medium, provided the original work is properly cited.

This paper mainly studies the optimization design of toll plaza, including the determination of the number of tollbooths and the design of the shape and size of the toll plaza. The optimization objectives are the construction cost of toll plaza, the throughput, and the accident rate. Through the analysis on the structure of toll plaza and the traffic flow, we determine the impact factors for optimization targets and select the number of tollbooths, the length of entrance and exit queue area, and the ingress and egress angles as decision variables and then build the function relationship between construction cost, accident rate, throughput, and decision variables. Then based on those functions to build the mathematical programming model, so as to get the optimal design plan.

\section{Introduction}

The design of the toll plaza of highways may directly affect the passage of vehicles and the accident occurrence possibility and at the same time determine the construction investment of the toll plaza. The design with insufficient consideration may not only lead to large construction cost but also result in such problems as traffic jam, high accident rate, and environment pollution. Especially nowadays with rapid increase of holding quantity of vehicles and the innovation of driving technology, under the condition that it cannot change the original highway lanes, how to design the toll plaza reasonably and guarantee the smooth passage of vehicles are the problems to be solved.

The progress of science and technology has an impact on charging methods. On the one hand, there was only one toll collection type in the original design, which was human-staffed manner. However, there are three kinds of toll collection manners existing nowadays: human-staffed, automated, and electronic toll collection. Hence, the design of tollbooths shall be changed. On the other hand, the number of autopilot cars is increasing. Usually, the autonomous vehicles may adopt the electronic toll collection manner. This trend will necessarily affect the design of toll plaza.
In order to guarantee the throughput in entrance area, in the original design, it basically adopted the method to set up more tollbooths. But, too many tollbooths result in the increase of the land area of the toll plaza which increases the construction cost. On the other hand, it increased the lane merging times for vehicles in the exit area, which is easier to cause the occurrence of accident.

So, there is a dilemma in the design of toll plaza. On the one hand, in order to improve the throughput, toll stations need to be increased. On the other hand, the increase of toll station will increase the construction cost and may increase the accident rate.

In this paper, the throughput of vehicles, the construction cost, and the occurrence possibility of accident are selected as the indicators to be optimized. Through the analysis on the structure of toll plaza and the traffic flow, the number of tollbooths, the length of entrance and exit queue area, and the ingress and egress angle are determined as decision variables. Based on the function relationship between construction cost, throughput, accident rate, and decision variables, we build the mathematical programming model and achieve the minimum value of the construction cost and accident rate under the condition of ensuring the throughput of the toll plaza, and the optimal design scheme of toll plaza is obtained. 


\section{Related Work}

The research on toll plaza mainly includes four aspects: driver behavior, security of toll plaza, service level of toll plaza, and design of toll plaza.

2.1. Research on Driver Behavior. The most common driver behavior is the shortest path selection, which can be applied by using spanning tree in graph theory. Some literatures use polynomial logit model [1], mixed model of random effects [2], and XCS learning algorithm [3] to study the driver's lane selection [4] and the influence of road signs [5]. It is found that both dynamic information signs and road signs can reduce unsafe driving behaviors.

2.2. Research on the Security of Toll Plaza. By use of the timevarying mixed model and logit model, Lu et al. [6, 7] found that the crash risk of vehicles in the diversion area of toll plaza is the highest. Valdés et al. [8] and Abuzwidah and Abdel-Aty $[9,10]$ compared the security of different types of toll plaza. Jehad et al. [11] used VIS-SIM simulation model to design toll plaza to improve security.

2.3. Research on Service Level of Toll Plaza. Abdul Majid et al. [12], Mahdi et al. [13, 14], and Ozmen-Ertekin et al. [15] used the Markov chain system to study the factors that cause congestion and service level decline in Toll Plaza and found that the main factors include waiting queue length, delay time, and heavy vehicles. Jack and Haitham [16] used analytic hierarchy process to evaluate the service level of eight different toll plazas. Lin et al. [17] divided the service level of toll plaza into six levels according to the queue length and passing time of toll plaza.

2.4. Research on the Design of Toll Plaza. There are two aspects in the design of toll plaza. One is based on network topology index calculation and uses information technology to design toll station management system, including Internet of things [18], XBee wireless transceiver [19], electronic toll collection system [20], and vehicular ad hoc network [21] to observe and adjust the traffic flow. The other one is to target the throughput of toll plaza [22,23] or cost and security [24], used discrete model [25], nonlinear integer programming [26], cellular automata [27, 28], ALINEA [29, 30], and multiple linear regression [31] to optimize the lane width, lane configuration, and queue length of toll plaza [32].

\section{Model}

The structure of toll plaza is shown in Figure 1.

Obviously, in one side of the isolation zone, vehicles may only move towards one direction. Therefore, it is enough to design the model of toll plaza in one side of the isolation zone; as to the other side, what needs we do is only change the parameters to produce a similar design (both sides are not necessarily symmetrical).
Let us select the lower part to analyze. Vehicles move from the left to the right, so the left part is the entrance of the toll plaza and the right part is the exit. The toll plaza is divided into five parts from the left to the right: fan-out area, entrance queue area, tollbooths area, exit area, and fan-in area. That is to say, we need to design those five parts to maximize the throughput, minimize the construction cost, and the accident rate.

Within a certain period of time, a certain number of different vehicles move into the toll plaza from the left, arrive at fan-out area, queue up to pay in entrance queue area based their own types, pass the tollbooth after paying toll, and then drive through the exit queue area and fan-in area to enter the lane.

During that driving course, there are two constraint nodes on vehicles: tollbooths and exit lanes. First of all, from the direction of entrance, if the tollbooths are too few, the vehicles will wait in the entrance queue area, increasing the queue length and the waiting time; hence, it needs a larger queue area, increasing the land acquisition expense of toll plaza. Therefore, the increase of tollbooths may shorten the queue length and reduce the land area of toll plaza. However, if there are too many tollbooths, on the one hand, the construction cost of tollbooth will be increased, and the width of toll plaza will be increased too due to the increase of tollbooth; hence, the land acquisition expense will be increased. On the other hand, too many tollbooths may increase the confluence extent of vehicles in fan-out area and hence increases the accident rate. At the same time, from the direction of entrance, the increase of tollbooth may lead to the increase of traffic flow in entrance area within the unit time, while the number of egress lanes is usually less than that of tollbooth, which may result in the confluence of more vehicles. As a result, it may cause a traffic jam, increase the waiting time and queue length, and reduce the throughput or increase the land acquisition expense due to the addition of the size of toll plaza. On the other hand, there will be more vehicles joining in the fan-in area, which may improve the accident rate.

3.1. Construction Cost. Construction cost mainly includes land acquisition expense and tollbooth construction cost. Where there are less tollbooths, there will be a longer queue in entrance area, hence reducing the throughput and increasing the land acquisition expense of entrance area. While if there are more tollbooths, on the one hand, the construction cost of tollbooth is directly proportional to the number of tollbooths, and on the other hand, it may reduce the throughput and increase the land acquisition expense of tollbooth, and at the same time, it may result in a longer queue in exit area, hence increasing the land acquisition expanse of exit area. Therefore, whether there are too many or too few tollbooths, the construction cost of the toll plaza will be increased.

The construction cost is determined by the number of tollbooths, the length of queue area, and its angle, that is, the function: 


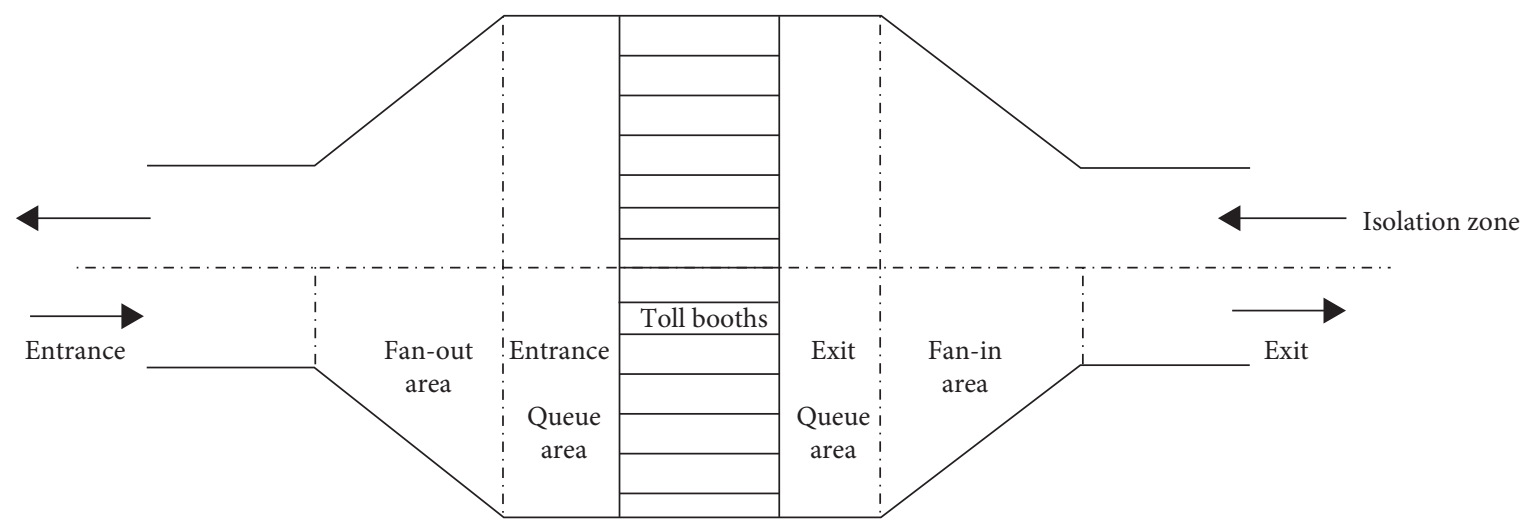

Figure 1: The structure of the toll plaza.

$$
\operatorname{Cost}_{B}=f\left(B_{1}, B_{2}, B_{3}, L_{E N}, L_{E X}, \theta_{E N}, \theta_{E X}\right),
$$

where $\operatorname{Cost}_{B}$ is the construction cost of toll plaza and $B_{i}(i=$ $1,2,3)$ is the number of three kinds of tollbooth. As shown in Figure 2, $L_{E N}$ and $L_{E X}$ are the length of queue area in fan-out area and fan-in area and $\theta_{E N}$ and $\theta_{E X}$ are the angles of fanout area and fan-in area.

Assuming the unit price for land acquisition is $c$ US\$/ sq.m, the land acquisition expense is

$$
c\left[\left(L_{E N}+L_{E X}\right) \cdot H+\left(H+W_{L}\right)\left(H-W_{L}\right)\left(\cot \theta_{E N}+\cot \theta_{E X}\right) H_{T B} W_{T B} B\right],
$$

where $H_{T B}$ is the length of the tollbooth, $W_{T B}$ is the width of the tollbooth, $B$ is the total number of the tollbooth, $H$ is the total width of the toll plaza, and $W_{L}$ is the width of the single direction of highways.

Assume the construction cost of three kinds of tollbooths is $c_{T B}^{i}(i=1,2,3)$, then the construction cost of the toll booth is

$$
\sum_{i=1}^{3}\left(c_{T B}^{i} \cdot B_{i}\right)
$$

Hence, the construction cost function is

$$
\begin{aligned}
\operatorname{Cos} t_{B}= & c\left[\left(L_{E N}+L_{E X}\right) \cdot H+\left(H+W_{L}\right)\left(H-W_{L}\right)\left(\cot \theta_{E N}\right.\right. \\
& \left.\left.+\cot \theta_{E X}\right)+H_{T B} W_{T B} B\right]+\sum_{i=1}^{3}\left(c_{T B}^{i} \cdot B_{i}\right) .
\end{aligned}
$$

3.2. Throughput of Toll Plaza. Throughput refers to the number of vehicles passing through the toll plaza within certain period of time, and it is determined by the passing speed, time of vehicles, density of traffic flow, etc. It is evident that the longer vehicles waiting in toll plaza, the lower the throughput. Because we also need to consider the construction cost of the toll plaza, when the waiting time is directly proportional to the queue length, the throughput may be determined by the queue length, and the longer the queue length is, the longer vehicles will wait and the lower the throughput will be. Vehicles mainly queue at two points. The first is in the entrance area before the tollbooth, and the more the tollbooths are, the shorter each queue and the larger the throughput will be. The second point is in the exit area before vehicles entering into lanes. The more the tollbooths are, the more vehicles entered into exit area, the longer the queue and the waiting time will be, hence the smaller the throughput will be. If the exit queue area cannot accommodate the queue, it will cause the traffic jam in entrance area, so as to reduce the throughput. Therefore, too few tollbooths may result in the increase of queue length in entrance area, while too many tollbooths may lead to the increase of queue length in exit area, both of which will reduce the throughput.

When vehicles enter into the fan-out area of the toll plaza, they shall pay the toll to pass the tollbooth. The more the tollbooths, the higher the total service rate. The shorter the queue length, the larger the throughput. On the contrary, the longer the queue length, the smaller the throughput. Thus there exists the following function relationship between the number of tollbooths and the queue length:

$$
D_{E N}=g_{E N}\left(\lambda_{E N}, B_{1}, B_{2}, B_{3}\right)
$$

where $D_{E N}$ is the number of vehicles queuing in fan-out area and $\lambda_{E N}$ is the average arriving rate of vehicles moving into fan-out area.

While if the reserved length of entrance queue area is shorter than the actual queue length, it will cause the vehicles followed have to stop on the highways with fewer lanes, which will lead to more traffic jam. Therefore, the length of entrance queue area shall meet:

$$
L_{E N} \geq D_{E N} \cdot h=g_{E N}\left(\lambda_{E N}, B_{1}, B_{2}, B_{3}\right) \cdot h,
$$

where $L_{E N}$ is the length of queue area in fan-out area and $\lambda_{E N}$ is the average arriving rate of vehicles moving into fan-out area.Assume the arriving number of vehicles within certain period of time is, then the average arriving rate is $\lambda_{E N}$. Assume the ratio of three kinds of vehicles are $k_{1}, k_{2}$, and $k_{3}$, the service rate of three kinds of toll booths are $\mu_{1}, \mu_{2}$, and $\mu_{3}$, respectively. Then, based on $M / M / B$ models, the function relationship between the number of 


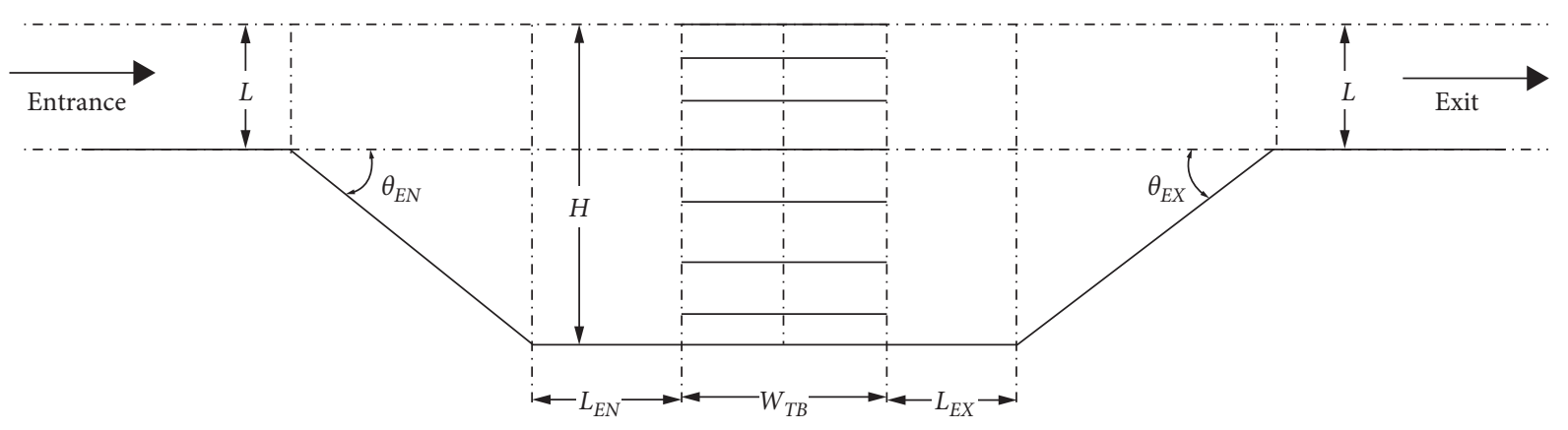

Figure 2: Figure of symbol.

each kind of vehicles queuing up and the number of tollbooths is

$$
D_{E N}^{i}=\frac{\left(B_{i} \rho_{i}\right)^{B_{i}} \rho_{i}}{B_{i} !\left(1-\rho_{i}\right)^{2}} P_{0}^{i}+B_{i} \rho_{i},
$$

where

$P_{0}^{i}=\left[\sum_{k=0}^{B_{i}-1}(1 / k !)\left(B_{i} \rho_{i}\right)^{k}+\left(1 / B_{i} !\right) \cdot\left(1 /\left(1-\rho_{i}\right)\right) \cdot\left(B_{i} \rho_{i}\right)^{B_{i}}\right]$ and $\rho_{i}=\left(\lambda_{E N}^{i} / \mu_{i}\right), \lambda_{E N}^{i}=k_{i} \cdot \lambda_{E N}$.

Because the $M / M / B$ model is a single queue, the number of actual queue of vehicles shall be divided by the number of the toll booth, so the actual number of vehicles queuing up is

$$
A D_{E N}^{i}=\left[\frac{D_{E N}^{i}}{B_{i}}+1\right] .
$$

In order to save up the land area, let us take the length of queue area as the actual length of vehicles queuing up, then

$$
L_{E N}=h \cdot \max _{1 \leq i \leq 3}\left\{A D_{E N}^{i}\right\} .
$$

In the fan-in area, the incoming vehicles have paid the toll. If there are more tollbooths, then there will be more vehicles moving into the fan-in area in unit time. When driving into the lanes, the large traffic flow will form a "bottleneck," cause traffic jam, increase the queue length, and reduce the throughput. Consequently, there exists a function relationship between the number of tollbooths and the queue length:

$$
D_{E X}=g_{E X}\left(\lambda_{E X}, B_{1}, B_{2}, B_{3}\right),
$$

where $D_{E X}$ is the number of vehicles queuing in fan-in area, and $\lambda_{E X}$ is the average arriving rate of vehicles moving into fan-in area.

Obviously, if the reserved length of exit queue area is shorter than the actual queue length, it will cause the vehicles following cannot pass through the tollbooth, which will reduce the throughput further. Therefore, the length of exit queue area shall meet:

$$
L_{E X} \geq D_{E X} \cdot h=g_{E X}\left(\lambda_{E X}, B_{1}, B_{2}, B_{3}\right) \cdot h,
$$

where $L_{E X}$ is the length of queue area in fan-in area and $h$ is the length of vehicles.
When vehicles leave the toll plaza, there is no need to distinguish their types. Hence, under the condition that the egress lanes are definite, the queue length in fan-in area is determined by the total incoming traffic flow. While the vehicles in fan-in area are those having paid the toll, so the traffic flow is related to the number of tollbooths.

If the arriving number of certain type of vehicles before the entrance $k_{i} X$ is not more than the total service rate of this kind of tollbooth, which means the work of the tollbooth is not at full load, then the number of vehicles entering into fan-in area is the number of vehicles at the entrance $k_{i} X$.

If the arriving number of certain type of vehicles before the entrance $k_{i} X$ is more than the total service rate of this kind of tollbooth, which means the work of the tollbooth is at full load, then the number of vehicles entering into fan-in area is $c_{i} \mu_{i}$.

Hence, the probability distribution sequence of vehicles arriving at the fan-in area is as follows:

\begin{tabular}{ccccc}
\hline$Y$ & $X$ & $\left(k_{1}+k_{2}\right) X_{3}+c_{3} \mu_{3}$ & $\ldots$ & $c_{1} \mu_{1}+c_{2} \mu_{2}+c_{3} \mu_{3}$ \\
\hline$p$ & $P_{1}^{0} P_{2}^{0} P_{3}^{0}$ & $P_{1}^{0} P_{2}^{0} P_{3}^{1}$ & $\ldots$ & $P_{1}^{1} P_{2}^{1} P_{3}^{1}$ \\
\hline
\end{tabular}

where $P_{i}^{0}=P\left(k_{i} X<c_{i} u_{i}\right)$ and $P_{i}^{1}=1-P_{i}^{0}(i=1,2,3)$.

Thus, the average arriving rate of vehicles in fan-out area is

$$
\lambda_{E X}=E(Y)=P_{1}^{0} P_{2}^{0} P_{3}^{0} \cdot X+\cdots+P_{1}^{1} P_{2}^{1} P_{3}^{1} \cdot\left(c_{1} \mu_{1}+c_{2} \mu_{2}+c_{3} \mu_{3}\right) .
$$

We have known the number of lanes is $L$, whose total service rate is the arriving rate of vehicles to the entrance $\lambda$, based on $M / M / L$ model, there will be

$$
D_{E X}=\frac{(L \rho)^{L} \rho}{L !(1-\rho)^{2}} P_{0}+L \rho,
$$

where $P_{0}=\left[\sum_{k=0}^{L-1}(1 / k !)(L \rho)^{k}+(1 / L !) \cdot(1 /(1-\rho)) \cdot(L \rho)^{L}\right]$ and $\rho=\left(\lambda_{E X} / \lambda\right)$.

In the same way with fan-out area, the queue length in the fan-in area is

$$
L_{E X}=h \cdot\left[\frac{D_{E X}}{B+1}\right] .
$$

3.3. Accident Rate. In the toll plaza, the occurrence of accident is mainly due to the confluence of vehicles. As shown in the Figure 1, vehicles confluence mainly happens 
in the fan-out area after the entrance and the fan-in area before the exit. Apparently, if there are more tollbooths, the confluence extent of vehicles in fan-out area and fanin area will be higher, and then the possibility of accident occurrence will be larger. And, if the ingress and egress angle in entrance fan-out area and exit fan-in area is larger, then the buffer extent will be smaller, and the possibility of accident occurrence will be larger. So, the increase of tollbooth, and the enlarging of ingress and egress angle may increase the possibility of accident occurrence.

So, the accident rate in fan-out area and fan-in area may be descried by the following function:

$$
\begin{aligned}
& I_{E N}=\varphi_{E N}\left(B-L, \theta_{E N}\right), \\
& I_{E X}=\varphi_{E X}\left(B-L, \theta_{E X}\right),
\end{aligned}
$$

where $B=\sum_{i=1}^{3} B_{i}$.

Assume one toll booth corresponds to one lane, obviously, when vehicles move into corresponding type of tollbooth, they only need to move straightly. So, the upper limit of the times to change the lane is $B-L$.

Then, the upper limit of merging times in unit time and unit area in fan-out area and fan-in area are

$$
\begin{array}{r}
\text { entrance : } I_{E N}=\frac{\lambda_{E N}(B-L)}{S_{E N} / T_{E N}}, \\
\text { exit: } I_{E X}=\frac{\lambda_{E X}(B-L)}{S_{E X} / T_{E X}},
\end{array}
$$

where $T_{E N}$ and $T_{E X}$ are the waiting time for vehicles in fanout area and fan-in area, respectively, and they meet:

$$
\begin{aligned}
& T_{E N}=\frac{D_{E N}}{\lambda_{E N}}, \\
& T_{E X}=\frac{D_{E X}}{\lambda_{E X}} .
\end{aligned}
$$

Thus,

$$
\begin{gathered}
I_{E N}=\frac{\lambda_{E N}^{2}(B-L)}{S_{E N} \cdot D_{E N}}, \\
I_{E X}=\frac{\lambda_{E X}^{2}(B-L)}{S_{E X} \cdot D_{E X}} .
\end{gathered}
$$

Assume the probability of accident occurrence with each lane merging is $P_{I}$ and the loss for each accident is $C_{I}$. The useful life of the toll plaza is $T$ (hours), then the possible loss due to the traffic accident happened in fan-out area and fanin area is

$$
\begin{aligned}
& \text { Lost }_{E N}=I_{E N} P_{I} C_{I} T=\frac{\lambda_{E N}^{2}(B-L)}{S_{E N}\left(\theta_{E N}\right) \cdot D_{E N}} P_{I} C_{I} T, \\
& \text { Lost }_{E X}=I_{E X} P_{I} C_{I} T=\frac{\lambda_{E X}^{2}(B-L)}{S_{E X}\left(\theta_{E X}\right) \cdot D_{E X}} P_{I} C_{I} T,
\end{aligned}
$$

respectively.

When the average arriving rate of vehicles $\lambda$, the number of lanes $L$, and the number of tollbooth $B$ are definite,

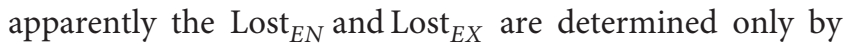
$\theta_{E N}$ and $\theta_{E X}$ and hence may minimize the loss of traffic accident through the decision of $\theta_{E N}$ and $\theta_{E X}$.

To sum up, the optimization design model of the toll plaza is

$$
\begin{aligned}
& \operatorname{Min} Z= c\left[\left(L_{E N}+L_{E X}\right) \cdot H+\left(H+W_{L}\right)\left(H-W_{L}\right)\left(\cot \theta_{E N}+\cot \theta_{E X}\right)+H_{T B} W_{T B} B\right] \\
&+\sum_{i=1}^{3}\left(c_{T B}^{i} \cdot B_{i}\right)+\frac{\lambda_{E N}^{2}(B-L)}{S_{E N}\left(\theta_{E N}\right) \cdot D_{E N}} P_{I} C_{I} T+\frac{\lambda_{E X}^{2}(B-L)}{S_{E X}\left(\theta_{E X}\right) \cdot D_{E X}} P_{I} C_{I} T, \\
& \text { s.t. }\left\{\begin{array}{l}
L_{E N}=h \cdot \operatorname{Max}_{1 \leq i \leq 3}\left\{A D_{E N}^{i}\right\}, \\
L_{E X}=h \cdot\left[\frac{D_{E X}}{B}+1\right] \\
B_{i}, L_{E N}, L_{E X} \geq 0, \\
0 \leq \theta_{E N}, \theta_{E X} \leq \frac{\pi}{2} .
\end{array}\right.
\end{aligned}
$$




\section{Solution}

Because $B_{1}, B_{2}$, and $B_{3}$ are only the integral values, $B_{1}, B_{2}$, and $B_{3}$ shall be calculated within $[1,20]$ based on the step size of 1 , which is to calculate the length of queue area in entrance area $L_{E N}$ under different mix of $\left(B_{1}, B_{2}, B_{3}\right)$ according to the formula (9).

Similarly, calculating within $[1,20]$ based on the step size of 1 to $B_{1}, B_{2}$, and $B_{3}$, we may get the traffic flow in entrance area $\lambda_{E N}$, the number of vehicles queuing up, and the length of queue area in exit area $L_{E X}$.

Based on the results $B_{1}, B_{2}, B_{3}, L_{E X}, D_{E X}$ and the formula (4), we may get the construction cost function of the toll plazaCos $t_{B}\left(\theta_{E N}, \theta_{E X}\right)$. Based on the formula (21), we may get the loss function for accident in entrance and exit area Lost $_{E N}\left(\theta_{E N}\right)$ and Lost $_{E X}\left(\theta_{E X}\right)$.

So, as to the objective function,

$$
\begin{aligned}
& Z=\operatorname{Cost}_{B}\left(\theta_{E N}+\theta_{E X}\right)+\operatorname{Lost}_{E N}\left(\theta_{E N}\right)+\operatorname{Lost}_{E X}\left(\theta_{E X}\right) \\
& =c\left(L_{E N} \cdot H+\frac{\left(W_{L}+H\right)\left(H-W_{L}\right)}{2 \tan \theta_{E N}}\right)+c\left(L_{E X} \cdot H+\frac{\left(W_{L}+H\right)\left(H-W_{L}\right)}{2 \tan \theta_{E X}}\right)+c \cdot S_{T B}+c_{T B} \cdot B \\
& +\frac{\lambda_{E N}^{2}(B-L) \cdot P_{I} C_{I} T}{\left(L_{E N} \cdot H+\left(\left(\left(W_{L}+H\right)\left(H-W_{L}\right)\right) /\left(2 \tan \theta_{E N}\right)\right)\right) \cdot D_{E N}}+\frac{\lambda_{E X}^{2}(B-L) \cdot P_{I} C_{I} T}{\left(L_{E X} \cdot H+\left(\left(\left(W_{L}+H\right)\left(H-W_{L}\right)\right) /\left(2 \tan \theta_{E X}\right)\right)\right) \cdot D_{E X}}, \\
& F_{E N}=\frac{\lambda_{E N}^{2}(B-L) \cdot P_{I} C_{I} T}{D_{E N}} \\
& F_{E X}=\frac{\lambda_{E X}^{2}(B-L) \cdot P_{I} C_{I} T}{D_{E X}} \\
& G=\frac{\left(W_{L}+H\right)\left(H-W_{L}\right)}{2} \\
& \text { Letting }\left\{\begin{array}{l}
\frac{\partial Z}{\partial \theta_{E N}}=-G \csc ^{2} \theta_{E N}\left(c-\frac{F_{E N}}{\left(L_{E N} H+G \cot \theta_{E N}\right)^{2}}\right)=0, \\
\frac{\partial Z}{\partial \theta_{E X}}=-G \csc ^{2} \theta_{E X}\left(c-\frac{F_{E X}}{\left(L_{E X} H+G \cot \theta_{E X}\right)^{2}}\right)=0,
\end{array}\right. \\
& \text { we have }\left\{\begin{array}{l}
\tan \theta_{E N}=\frac{G}{\sqrt{\left(F_{E N} / c\right)-L_{E N} \cdot H}}, \\
\tan \theta_{E X}=\frac{G}{\sqrt{\left(F_{E X} / c\right)-L_{E X} \cdot H}},
\end{array}\right.
\end{aligned}
$$

4.1. Simulation. According to the highway toll station and toll plaza design specifications and survey results, the following assumptions are made for the initial data, as shown in Table 1.

According to the above algorithm, we can get 8000 kinds of results, some of which are listed in Table 2 .

Table 2 shows, along with the increase of the number of tollbooths, the length of exit queue area increases too, leading to the increase of the land acquisition expense. Therefore, after comprehensive comparison, the result of $\left(B_{1}, B_{2}, B_{3}\right)=(3,3,1)$ not only may guarantee the preferable throughput but also minimize the total expanse.
Thus, when the arriving rate of vehicles is 1800 vehicles/ hour, the type ratio of vehicles is $1: 1: 1$ and the optimized design plan is as follows: the number of human-staffed, exactchange, and electronic tollbooths are 3, 3, and 1, respectively, and 7 in total; the length of entrance queue area and that of the exit queue area are both 5 meters; the angle of ingress is $14.43^{\circ}$ and that of the egress is $6.53^{\circ}$. In this design plan, the total expense is minimum, which is US\$ 29.73 million.

4.2. Sensitivity Analysis. Because the traffic flow is a random variable, under the condition that the ratio of different kinds 
TABLe 1: Initial data.

\begin{tabular}{|c|c|c|c|}
\hline Toll type & Conventional toll booths & Exact-change toll booths & Electronic toll collection booths \\
\hline Service rate & 350 vehicles $/ \mathrm{h}$ & 550 vehicles $/ \mathrm{h}$ & 1200 vehicles $/ \mathrm{h}$ \\
\hline Arriving rate & 600 vehicles $/ \mathrm{h}$ & 600 vehicles/h & 600 vehicles/h \\
\hline Road width & & $3.5 \mathrm{~m}$ & \\
\hline Width of tollbooth & & $5.8 \mathrm{~m}$ & \\
\hline Length of tollbooth & & $4.2 \mathrm{~m}$ & \\
\hline Length of vehicles & & $5.0 \mathrm{~m}$ & \\
\hline The land acquisition expense & & $2200 \$\left(\mathrm{~m}^{2}\right)$ & \\
\hline Useful life & & 20 years & \\
\hline Construction expense & $58400 \$$ (per) & $71700 \$$ (per) & $83300 \$$ (per) \\
\hline
\end{tabular}

Table 2: Part of design plan.

\begin{tabular}{lccccccc}
\hline No. & $\left(B_{1}, B_{2}, B_{3}\right)$ & $L_{E N}(\mathrm{~m})$ & $L_{E X}(\mathrm{~m})$ & $\theta_{E N}$ & $\theta_{E X}$ & Cost $_{B}($ million$)$ & Lost $_{E N}+$ Lost $_{E X}(\mathrm{million})$ \\
\hline 1 & $(3,2,1)$ & 5 & 5 & $12.00^{\circ}$ & $6.32^{\circ}$ & 12.88 & 17.39 \\
2 & $(3,3,1)$ & 5 & 10 & $14.43^{\circ}$ & $6.53^{\circ}$ & 15.34 & 14.39 \\
3 & $(4,2,1)$ & 5 & 5 & $14.43^{\circ}$ & $6.90^{\circ}$ & 14.88 & 21.45 \\
4 & $(4,3,1)$ & 5 & 15 & $17.03^{\circ}$ & $7.10^{\circ}$ & 17.67 & 13.70 \\
5 & $(5,2,1)$ & 5 & 10 & $17.03^{\circ}$ & $7.46^{\circ}$ & 17.15 & 16.42 \\
\hline
\end{tabular}

TABLE 3: The sensitivity analysis on traffic flow.

\begin{tabular}{lcccccc}
\hline$\lambda_{E N}$ & 800 & 900 & 1000 & 2000 & 2500 & 2600 \\
\hline$\left(B_{1}, B_{2}, B_{3}\right)$ & $(3,2,1)$ & $(3,3,1)$ & $(3,3,1)$ & $(3,3,1)$ & $(3,3,1)$ & $(4,3,1)$ \\
\hline
\end{tabular}

TABLE 4: The sensitivity analysis on vehicles ratio.

\begin{tabular}{|c|c|c|c|c|c|c|c|}
\hline Vehicles ratio & $\left(B_{1}, B_{2}, B_{3}\right)$ & $L_{E N}(\mathrm{~m})$ & $L_{E X}(\mathrm{~m})$ & $\theta_{E N}$ & $\theta_{E X}$ & $\operatorname{Cost}_{B}$ (million) & Lost $_{E N}+$ Lost $_{E X}$ (million) \\
\hline $1: 1: 2$ & $(3,2,1)$ & 10 & 5 & $18.9^{\circ}$ & $6.32^{\circ}$ & 8.95 & 15.61 \\
\hline $1: 1: 2$ & $(3,3,1)$ & 10 & 10 & $22.6^{\circ}$ & $6.53^{\circ}$ & 10.76 & 12.35 \\
\hline $1: 1: 2$ & $(4,3,1)$ & 10 & 15 & $26.4^{\circ}$ & $6.90^{\circ}$ & 12.57 & 11.40 \\
\hline $1: 1: 10$ & $(1,1,2)$ & 10 & 5 & $13.43^{\circ}$ & $5.01^{\circ}$ & 5.22 & 9.84 \\
\hline $1: 1: 10$ & $(2,2,2)$ & 10 & 15 & $18.92^{\circ}$ & $11.90^{\circ}$ & 9.73 & 14.03 \\
\hline
\end{tabular}

of vehicles is $1: 1: 1$, changing the average arriving rate of vehicles and observing its effect on the optimized design plan may produce Table 3:

Table 3 shows, when the average arriving rate of vehicles within $[900,2500]$, the setup of $(3,3,1)$ is the optimized plan, which proves this plan has a wide permissible range of traffic flow. Even the traffic flow is small, as long as it is not less than 900 vehicles/hour, there will no tollbooth in idle; as to the large traffic flow, as long as it is not more than 2500 vehicles/hour, there will no traffic jam in the toll plaza to affect the throughput.

Along with the progress of technology, the autonomous vehicles increase, and inevitably, the autonomous vehicles must use electronic tollbooth. Therefore, under the condition that the arriving rate of vehicles still is 1800 vehicles/ hour, changing the ratio of different types of vehicles may produce the results as shown in Table 4.

Table 4 shows, with the arriving rate of vehicles unchanged, when the ratio of using electronic toll-paying manner increases to $1: 1: 2$, if still sticking to set 1 electronic toll collection booth, there will be traffic jam at the entrance, and the throughput is reduce. This is because that the vehicles using electronic toll-paying manner usually have high speed, if there is fewer tollbooth, the vehicles will absolutely queue up. At the same time, the table shows traffic jam will increase the length of entrance queue area, but the angle of entrance may be increased, because the electronic tollbooth is mainly set on the straight lane, most vehicles may keep their way in straight lane. As a result, increase the entrance angle may reduce the construction cost. In comprehensive, the optimized design for three types of tollbooths is still the set of $(3,3,1)$. When the ratio of vehicles changes to be $1: 1: 10$, it may add the electronic toll collection booths and reduce the human staffed and exact-change tollbooths, which may reduce the width of the toll plaza and the times for vehicles to change the lanes without enlarging the length of entrance and exit queue area; thus, it greatly reduce the construction cost and the accident loss, in which the optimized design of three kinds of tollbooths is $(1,1,2)$.

\section{Conclusion}

By describing the function relationships between the construction cost, throughput, accident rate, and number of tollbooths, the length of entrance and exit queue area, the 
ingress and egress angle, the mathematical programming model built by us has a large universality. Only inputting such initial data as the arriving rate of vehicles, the ratio of different type of vehicles, the service rate of tollbooths, and the land acquisition expense etc., you may get a complete design plan for the toll plaza, including the number of tollbooths and their ratio, the shape, the size of the plaza, etc.

Under certain initial conditions, the design plan of the toll plaza we get from the model also has strong robustness. It may guarantee the throughput of the plaza and avoid the idling of tollbooths in a large permissible range of traffic flow, which proves that the model we build is solid.

\section{Data Availability}

The data are used to support the study are available within the article.

\section{Conflicts of Interest}

The authors declare that there are no conflicts of interest regarding the publication of this paper.

\section{Acknowledgments}

This work was supported by the Major Quality Engineering Projects in Anhui Province (2018jyxm1403).

\section{References}

[1] H. Parmar, P. Chakroborty, and D. Kundu, "Modelling automobile drivers' toll-lane choice behaviour at a toll plaza using mixed logit model," Procedia-Social and Behavioral Sciences, vol. 104, pp. 593-600, 2013.

[2] M. Saad, M. Abdel-Aty, and J. Lee, "Analysis of driving behavior at expressway toll plazas," Transportation Research Part F, vol. 61, pp. 1-15, 2018.

[3] B. Bartin, "Use of learning classifier systems in microscopic toll plaza simulation models," IET Intelligent Transport Systems, vol. 13, no. 5, pp. 860-869, 2019.

[4] A. Dubedi, P. Chakroborty, D. Kundu, and K. Harikishan Reddy, "Modeling automobile drivers' toll-lane choice behavior at a toll plaza," Journal of Transport Engineering, vol. 138, no. 12, pp. 1350-1357, 2012.

[5] S. Gaca, M. Kieć, S. Pogodzińska, and A. Wontorczyk, "Impact of toll plazas road marking and signs on drivers' behaviour," MATEC Web of Conferences, vol. 231, 8 pages, Article ID 02003, 2018.

[6] X. Lu, J. He, M. Abdel-Aty, Y. Wu, and J. Yuan, “Time-varying analysis of traffic conflicts at the upstream approach of toll plaza," Accident Analysis and Prevention, vol. 141, no. 4, pp. 1-14, 2020.

[7] L. Xing, J. He, M. Abdel-Aty, Q. Cai, Y. Li, and O. Zheng, "Examining traffic conflicts of up stream toll plaza area using vehicles' trajectory data," Accident; Analysis and Prevention, vol. 125, no. 1, pp. 174-187, 2019.

[8] D. Valdés, B. Colucci, M. Knodler et al., "Comparative analysis of toll plaza safety features in Puerto Rico and Massachusetts with a driving simulator," Transportation Research Record: Journal of the Transportation Research Board, vol. 2663, no. 1, pp. 1-11, 2017.
[9] M. Abuzwidah and M. Abdel-Aty, "Safety assessment of the conversion of toll plazas to all-electronic toll collection system," Accident Analysis \& Prevention, vol. 80, no. 3, pp. 153-161, 2015.

[10] M. Abuzwidah and M. Abdel-Aty, "Crash risk analysis of different designs of toll plazas," Safety Science, vol. 107, no. 2, pp. 77-84, 2018.

[11] A. E. Jehad, A. Ismail, M. N. Borhan, and S. Z. Ishak, "Modelling and optimizing of electronic toll collection (ETC) at Malaysian toll plazas using microsimulation models," International Journal of Engineering \& Technology, vol. 7, no. 4, pp. 2304-2308, 2018.

[12] K. Abdul Majid, Z. Yusoff, and A. Aziz Jemain, "Queue analysis at toll plazas (inbound): a basic model for traffic systems towards a study of the effect on toll plazas with different arrival patterns," International Conference on Information and Communication Technology, pp. 5-9, 2016.

[13] M. B. Mahdi and L. V. Leong, "Assessment of queue length and delay at toll plaza using microscopic traffic simulation," Applied Mechanics and Materials, vol. 802, pp. 387-392, 2015.

[14] M. B. Mahdi, V. L. Lee, and M. S. Ahmad Farhan, "Use of microscopic traffic simulation software to determine heavyvehicle influence on queue lengths at toll plazas," Arabian Journal for Science and Engineering, vol. 12, 2019.

[15] D. Ozmen-Ertekin, K. Ozbay, S. Mudigonda, and A. M. Cochran, "Simple approach to estimating changes in toll plaza delays," Transportation Research Record: Journal of the Transportation Research Board, vol. 2047, no. 1, pp. 66-74, 2008.

[16] K. Jack and M. Al-D. Haitham, "Proposed level-of-service methodology for toll plazas," Transportation Research Record, vol. 1802, pp. 86-96, 2002.

[17] F. B. Lin and C.-W. Su, "Level-of-service analysis of toll plazas on freeway main lines," Journal of Transportation Engineering, vol. 120, no. 2, pp. 246-263, 1994.

[18] H Manjunath Singh, V Velantina, G Veda Bai, M. N. Varshini, and S. Padmavathi, "Reduction of traffic at toll plaza by automatic toll collection using rfid and gsm technology," International Journal of Current Engineering and Scientific Research, vol. 6, no. 6, pp. 187-192, 2019.

[19] R. Deepika, R. A. Kalpana, S. Meera, and R. Sharmikha Sree, "Advanced toll plaza monitoring by utilization of WSN modules," International Journal of Engineering \& Technology, vol. 7, no. 3, pp. 168-171, 2018.

[20] E. Gordin, J. Klodzinski, and C. D. Santos, "Safety benefits from deployment of open road tolling for main-line toll plazas in Florida," Transportation Research Record: Journal of the Transportation Research Board, vol. 2229, no. 1, pp. 85-92, 2011.

[21] S. Hussain, D. Wu, S. Memon, and N. K. Bux, "Vehicular ad hoc network (VANET) connectivity analysis of a highway toll plaza," Data, vol. 4, pp. 1-18, 2019.

[22] R. Neuhold, F. Garolla, O. Sidla, and M. Fellendorf, "Predicting and optimizing traffic flow at toll plazas," Transportation Research Procedia, vol. 37, pp. 330-337, 2019.

[23] C. Kim, D.-K. Kim, S.-Y. Kho, S. Kang, and K. Chung, "Dynamically determining the toll plaza capacity by monitoring approaching traffic conditions in real-time," Applied Sciences, vol. 87, no. 6, pp. 1-11, 2016.

[24] H. Dong, "The design of a toll plaza," in Proceedings of the 5th International Conference on Computer-Aided Design, Manufacturing, Modeling and Simulation, pp. 1-5, Busan, South Korea, April 2017. 
[25] M. A. d. F. Caldas and K. T. Sacramento, "Simulation model of discret events applied to the planning and operation of a toll plaza," Journal of Transport Literature, vol. 10, no. 3, pp. $40-44,2016$.

[26] S. Kim, "The toll plaza optimization problem: design, operations, and strategies," Transportation Research Part E: Logistics and Transportation Review, vol. 45, no. 1, pp. 125-137, 2009.

[27] H. Lin, J. Zhu, Y. Xiao, and L. Han, "Optimal design of toll plaza based on traffic flow cellular automata," in 4th International Conference on Information Science and Control Engineering, pp. 1066-1072, 2017.

[28] Y.-J. Liu, J. Cao, X.-Y. Cao, and Y.-B. Zhang, "Optimization of design scheme for toll plaza based on $\mathrm{M} / \mathrm{M} / \mathrm{C}$ queuing theory and cellular automata simulation algorithm," Modern Applied Science, vol. 11, no. 7, pp. 1-12, 2017.

[29] M. Papageorgiou, I. Papamichail, A. D. Spiliopoulou, and A. F. Lentzakis, "Real-time merging traffic control with applications to toll plaza and work zone management," Transportation Research Part C: Emerging Technologies, vol. 16, no. 5, pp. 535-553, 2008.

[30] D. Anastasia, "Spiliopoulou, ioannis papamichail, and markos papageorgiou. "Toll plaza merging traffic control for throughput maximization," Journal of Transportation Engineering, vol. 136, no. 1, pp. 67-76, 2010.

[31] R. F. Perry and S. M. Gupta, "Response surface methodology applied to toll plaza design for the transition to electronic toll collection," International Federation of Operational Research Societies, vol. 8, no. 3, pp. 707-726, 2001.

[32] D. R. McDonald Jr., R. E. Stammer Jr., and ASCE. Members, "Contribution to the development of guidelines for toll plaza design," Journal of Transportation Engineering, vol. 127, no. 3, pp. 215-222, 2001. 